\title{
Evaluation of the gray level of restorative materials using cone-beam computed tomography: A cross-sectional study
}

\section{Ocena poziomu szarości materiałów stomatologicznych w tomografii stożkowej - badanie przekrojowe}

\author{
Pezhman Hadadi ${ }^{1, A}$, Farzane Ostovarrad ${ }^{2, B}$, Ava Nikbin ${ }^{2, D-F}$, Hadi Ranjzad ${ }^{3, B}$, Farzane Ghasemi ${ }^{4, B}$, Somayeh Nemati ${ }^{2}, B$ \\ ${ }^{1}$ Department of Oral and Maxillofacial Radiology, Faculty of Dentistry, Guilan University of Medical Sciences, Anzali, Iran \\ 2 Department of Oral and Maxillofacial Radiology, Faculty of Dentistry, Guilan University of Medical Sciences, Rasht, Iran \\ ${ }^{3}$ Department of Prosthodontics, Faculty of Dentistry, Guilan University of Medical Sciences, Anzali, Iran \\ ${ }^{4}$ Faculty of Dentistry, Guilan University of Medical Sciences, Rasht, Iran \\ A - research concept and design; $\mathrm{B}$ - collection and/or assembly of data; $\mathrm{C}$ - data analysis and interpretation; \\ $D$ - writing the article; $E$ - critical revision of the article; $F$ - final approval of the article
}

\section{Address for correspondence}

Ava Nikbin

E-mail: nikbinava@yahoo.com

Funding sources

None declared

Conflict of interest

None declared

\section{Acknowledgements}

We would like to thank the employees of Ayatollah Rouhani Hospital, Iran, especially Dr. Mahdi Rahmani, for their cooperation.

Received on April 4, 2018

Reviewed on July 3, 2018

Accepted on July 18, 2018

DOI

10.17219/dmp/93569

Copyright

○ 2018 by Wroclaw Medical University

and Polish Dental Society

This is an article distributed under the terms of the

Creative Commons Attribution Non-Commercial License

(http://creativecommons.org/licenses/by-nc-nd/4.0/)

\begin{abstract}
Background. Densitometry plays an important role in the diagnosis of different types of dental materials and treatment planning. Due to diversity in density, equal amounts of different materials absorb various amounts of $X$-rays and yield different radiographic views.

Objectives. The aim of this study was to evaluate the gray scales of 5 commercially available restorative materials, including amalgam, composite resin, flowable composite resin, glass-ionomer, and Dycal.

Material and methods. Samples of the 5 test materials from various manufacturers were prepared, each 5-millimeter-thick. There were 7 glass-ionomer samples and 10 of each of the other materials, making a total of 47 samples in the study. The test materials were scanned using a Kodak cone-beam computed tomography (CBCT) unit. Subsequently, the gray scales were determined and evaluated by a radiologist using OnDemand3DTM Dental software and analyzed with SPSS v. 22 software.
\end{abstract}

Results. Amalgam had a higher gray scale than the other groups of restorative materials. In some cases, it was the same as that of composite resin; however, it was significantly different from gray scales of flowable composite resin, glass-ionomer and Dycal. It was concluded that composite resin and amalgam were high in gray scale, while flowable composite resin, glass-ionomer and Dycal exhibited low gray scales.

Conclusions. Amalgam and composite resin had high gray scales, and glass-ionomer and Dycal exhibited the lowest gray scale values. The findings show that CBCT can be helpful in differentiating amalgam and composite resin from other materials.

Key words: cone-beam computed tomography, dental materials, densitometry

Słowa kluczowe: stożkowa tomografia komputerowa, materiały dentystyczne, densytometria 


\section{Introduction}

One of the main issues playing an important role in the assessment of different dental materials and in treatment planning is densitometry. For example, distinguishing the density of bone undeniably affects the success of dental implants. ${ }^{1}$ In addition, in the case of maxillofacial trauma or a foreign body suspected in the surrounding soft tissue, densitometry can be used to determine the kind of the foreign body, which might be a restorative material. Densitometry is also useful while distinguishing restorative materials used in older treatment plans from each other and from the recent ones, which can be of great importance in dental treatment planning. ${ }^{2,3}$ Equal amounts of different materials, due to differences in their atomic number and density, result in differences in the attenuation of X-rays. As a result, they have different radiographic projections even on plain films. Therefore, given the density of any material, its nature can be determined through radiography. ${ }^{4}$ Denser materials have less space in their crystal networks and their molecules are highly compressed. These substances absorb much more X-ray radiation when they are exposed to $\mathrm{X}$-rays, since they have more atoms and more electrons. ${ }^{5,6}$

$\mathrm{X}$-rays are used to produce images from opaque materials based on the relationship between the density and X-ray absorption of different materials. ${ }^{7}$ Different techniques, such as computed tomography (CT) and conebeam computed tomography (CBCT) can be used.

In the CT technique, one number is assigned to each pixel displaying the images and this shows the rate of attenuation of rays by each tissue. Computed tomography numbers are known as Hounsfield units (HU). In 1978, this technique was introduced in bone densitometry. Various studies have recognized CT as the gold standard for tissue densitometry. ${ }^{8}$

The CBCT technique is of great importance in head and neck traumas. In recent years, CBCT has also been used as a critical diagnostic tool in dentistry $y^{9-13}$ and it is an innovative technique in scanning and data reconstruction. Cone-beam computed tomography is widely used for 3-dimensional and multiplanar images. Compared to CT, this method can provide detailed images - up to submillimeter resolution - in a shorter time and at a lower dosage; in addition, it is more affordable for patients. However, CBCT has shortcomings as well. The quality of reconstructed $\mathrm{CBCT}$ images is affected by noise, beam hardening, the cone-beam effect and photon starvation. These effects result in the formation of different types of artifacts, such as bright streaks of radiation, dark areas adjacent to metal objects or even a complete loss of gray shadows between adjacent metal objects. Beam hardening results from the preferential absorption of lowerenergy photons in a heterogeneous X-ray beam. As opposed to rectangular objects, in spherical and cylindrical objects, like the skull and implants, the distance through the center is longer than a path closer to the surface, the central area can appear as a dark area with a decreased CT number (HU) in the middle of axial cuts. ${ }^{14}$ Nevertheless, recent research shows that by analyzing gray scales, CBCT can determine HU of tissues and, as a result, the densities of different bones. ${ }^{14,15}$ There are limited studies on the use of CBCT to determine the density of restorative materials. ${ }^{15}$

The aim of this study was to evaluate the gray levels of materials in restorative dentistry, using CBCT in standard exposure, which could help to assess the materials, and thus improve treatment planning.

\section{Material and methods}

This pilot study is one of the first studies on evaluating the gray levels of dental restorative materials with the use of the CBCT technique. Each group of substances consisted of 10 different products from various manufacturers, except for the glass-ionomer group, which included 7 samples, making a total of 47 samples of restorative materials evaluated in 5 groups.

The technical specifications of the 5 substances, commonly used in restorative dentistry, evaluated in this study are as follows:

- amalgam: A - ANA $2000^{\circledR}$ ( Nordiska Dental, Ängelholm, Sweden); B - GS-80 ${ }^{\circledR}$ (SDI, Itasca, USA); C - Cinalux ${ }^{\circledR}$ (Shahid Faghihi, Tehran, Iran); D - GK ${ }^{\circledR}$ (AT\&M Biomaterials, Beijing, China); E - GK-110 ${ }^{\circledR}$ (AT\&M Biomaterials; F - Wykalloy ${ }^{\circledR}$ (Prestige Dental Products, Anaheim, USA); G - Aristaloy $21^{\circledR}$ (Lavadent, London, UK); $\mathrm{H}$ - World Work Powder Alloy ${ }^{\circledR}$ (World Work, Montebello Vicentino, Italy); I - Contour ${ }^{\circledR}$ (Kerr, Orange, USA); J - 110-Plus ${ }^{\circledR}$ (Anas Dental Supplies, Damascus, Syria); - composite resin: A - SDI Luna ${ }^{\circledR}$ (SDI, Itasca, USA); $\mathrm{B}$ - Coltene-Synergy ${ }^{\circledR}$ (Coltene Whaledent Inc., Cuyahoga Falls, USA); C - Filtek Z250-XT ${ }^{\circledR}$ (3M, Seefeld, Germany); D - Opallis ${ }^{\circledR}$ (FGM, Joinville, Brazil); E - Bisco-Aelite Aesthetic Enamel ${ }^{\circledR}$ (Bisco, Schaumburg, USA); F - Estelite Sigma Quick ${ }^{\circledR}$ (Tokuyama, Tokyo, Japan); G - Shofu-Beautifil II ${ }^{\circledR}$ (Shofu, Kyoto, Japan); H - Denfil ${ }^{\circledR}$ (Vericom, Anyang, South Korea); I - Diafil ${ }^{\circledR}$ (Diadent, Cheongju, South Korea); J - Charmfil Plus ${ }^{\circledR}$ (Dentkist, Seoul, South Korea);

- flowable composite resin: A - Denfil Flow ${ }^{\circledR}$ (Vericom); B - Diafil Flow ${ }^{\circledR}$ (Diadent); C - Denu Flow Resin ${ }^{\circledR}$ (HDIDenu, Seoul, South Korea); D - Permaflo Pink ${ }^{\circledR}$ (Ultra Dent, South Jordan, USA); E - Clearfil AP-X Flow ${ }^{\circledR}(\mathrm{Ku}-$ raray, Chicago, USA); F - Opallis Flow ${ }^{\circledR}$ (FGM); G - Heliomolar Flow ${ }^{\circledR}$ (Ivoclar Vivadent, Mississauga, Canada); $\mathrm{H}$ - Tetric N-flow ${ }^{\circledR}$ (Ivoclar Vivadent, Mumbai, India); I - Wave ${ }^{\circledR}$ (SDI, Itasca, USA); J - Filtek Z350-XT ${ }^{\circledR}(3 \mathrm{M})$;

- glass-ionomer: A - Riva Luting ${ }^{\circledR}$ (SDI, Bayswater, Australia); B - GC Fuji I ${ }^{\circledR}$ (GC, Tokyo, Japan); C - Tokuso Ionomer $^{\circledR}$ (Tokuyama); D - Chemfil Superior ${ }^{\circledR}$ (Dentsply, 
Tulsa, USA); E - Ionoseal $^{\circledR}$ (VOCO, Cuxhaven, Germany); F - Iono Cid-LC ${ }^{\circledR}$ (FSDS, Greenock, Canada); G - Glass Liner ${ }^{\circledR}$ (WP Dental, Barmstedt, Germany);

- Dycal: A - ACTIVA Bioactive-base/liner ${ }^{\circledR}$ (Pulpdent Corporation, Watertown, USA); B - Dycal Ivory ${ }^{\circledR}$ (Dentsply); C - ANA Liner ${ }^{\circledR}$ (Nordiska Dental, Ängelholm, Sweden); D - Biner-LC ${ }^{\circledR}$ (Meta Biomed, Cheongju, South Korea); E - Hidrox-Cal ${ }^{\circledR}$ (Maquira, Maringá, Brazil); F - Theracal LC ${ }^{\circledR}$ (Bisco); G - Ionosit-Baseliner ${ }^{\circledR}$ (DMG Chemisch-Pharmazeutische, Hamburg, Germany); $\mathrm{H}$ - Master Dent Cavity Liner ${ }^{\circledR}$ (Master Dent, Garden Grove, USA); I - Ultra Blend Plus ${ }^{\circledR}$ (Ultra Dent, South Jordan, USA); J - Charmfil Flow ${ }^{\circledR}$ (Dentkist).

To prepare the test set, a cardboard grid measuring $135 \times 60 \times 1 \mathrm{~mm}$ was selected and a collection of cubes with the same size $(5 \times 5 \times 5 \mathrm{~mm})$ was made of it (Fig. 1). The rows show the material types used and the columns show the manufacturers. Each material was placed in one of the cubes and the samples were prepared for final setting according to the same clinical procedure. The preparation procedures were as follows: amalgam samples were packed using a condenser, and composite resin samples were light-cured layer by layer; to light-cure flowable composite resin, glass-ionomer and Dycal, a light-curing unit was used (Fig. 2).

After the final setting, the restorative materials were separated from the cardboard grid and each group of materials was laid on a separate sheet. The composite resin, flowable composite resin, glass-ionomer, and Dycal samples were placed on 4 separate cardboards with a distance of $1.5 \mathrm{~cm}$ between them (Fig. 3). For the amalgam samples, a little more space was left between them (about $2 \mathrm{~cm}$ ) due to artifacts made by amalgam during image acquisition (Fig. 4). It should be pointed out that there was a limitation to the cardboard sheet size, since a larger size would have been out of the field of view of the CBCT system. In addition, since the space between the amalgam samples was more than that between other materials, each sample had to be scanned separately.

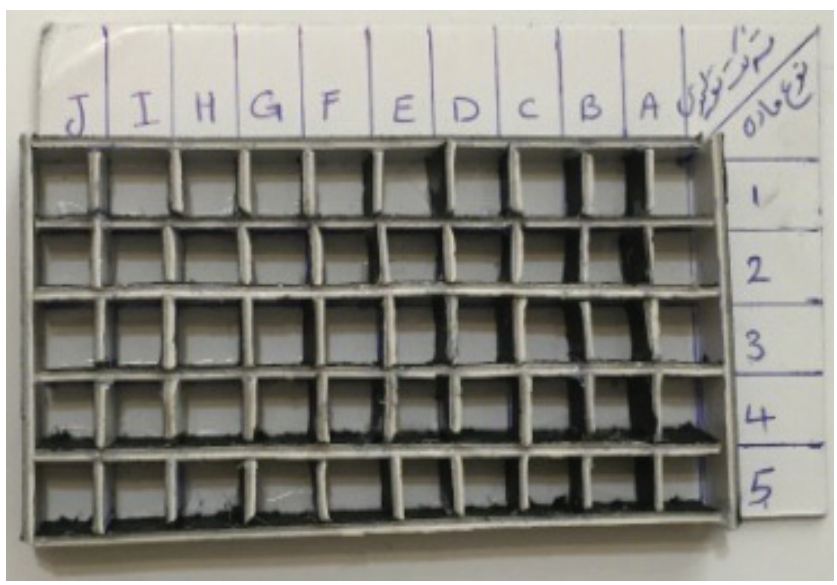

Fig. 1. A cardboard grid fabricated for the placement of the restorative materials

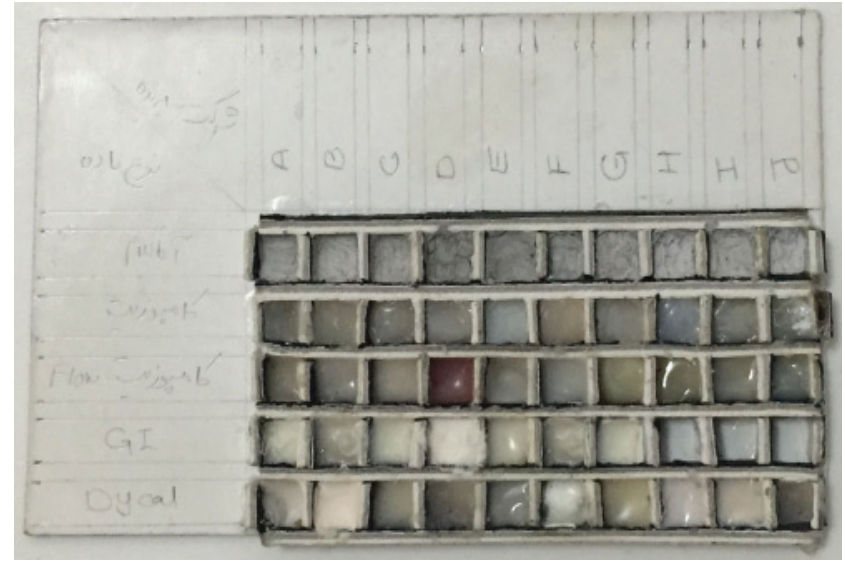

Fig. 2. Squares of the cardboard grid filled with the restorative materials



Fig. 3. A -composite resin; B - flowable composite resin; C - glass-ionomer; $D$ - Dycal cubes attached to the cardboard sheet with a distance of $1.5 \mathrm{~cm}$ between them

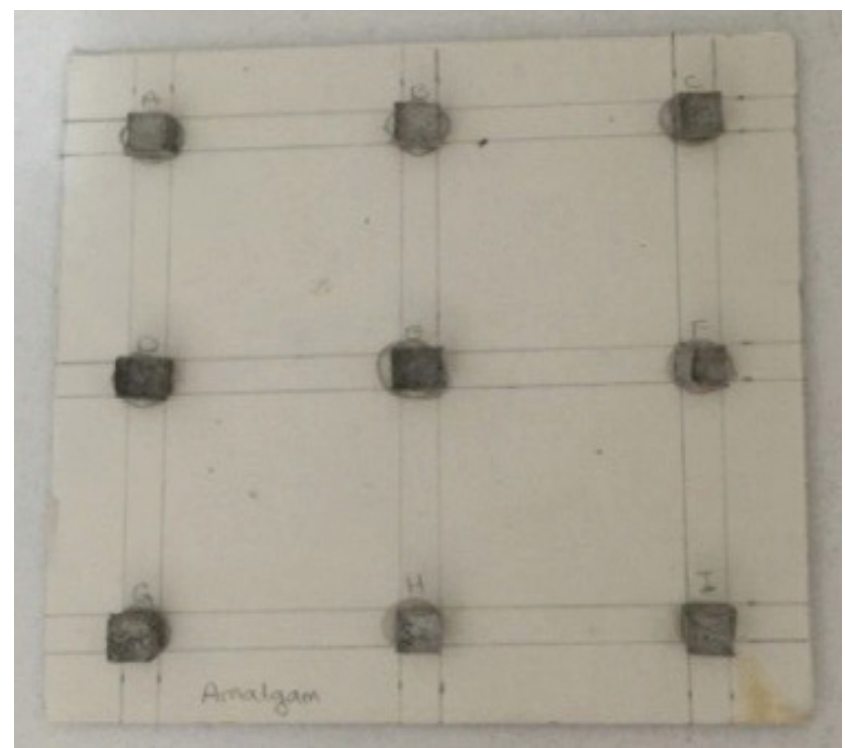

Fig. 4. Amalgam cubes attached to the cardboard sheet with a distance of $2 \mathrm{~cm}$ between them 
Each cardboard sheet holding 1 of the restorative materials was exposed to a CBCT system (Kodak CBCT, Carestream Company, Rochester, USA) under standard exposure conditions $(\mathrm{MA}=6.3, \mathrm{kVp}=73$, voxel $=180)$. The acquired images were analyzed by an experienced radiologist in a horizontal view, using OnDemand3D ${ }^{\mathrm{TM}}$ Dental software (Cybermed, Seoul, South Korea) and the gray scale of each sample was recorded by determining the mean, min and max values at the center of the sample (Fig. 5,6).

The gray levels were determined at the center of the samples to minimize the artifact effect. It should be pointed out that cubic and homogeneous samples were used in the present study to eliminate the beam-hardening effect, which is a problem in spherical, cylindrical and nonhomogeneous samples. The samples were completely identical and the artifact effect, if any, would affect them all similarly.



Fig. 5. The cone-beam computed tomography (CBCT) image of amalgam cubes scanned by a Kodak CBCT system
The data was recorded in checklists and analyzed with SPSS v. 22 software (IBM Corp., Armonk, USA). The gray scale was evaluated using means and standard deviations (SDs) at a $95 \%$ confidence interval (CI), separately for each dental material under standard exposure conditions. An analysis of variance (ANOVA) was used to compare the means of gray scales in the dental materials under exposure conditions and between different materials. Post-hoc Tukey's tests were used for two-by-two comparisons of the mean gray scale values of the dental materials. In the cases when the gray scale data was not normally distributed, corresponding non-parametric tests were used. Statistical significance was set at $\mathrm{p}<0.05$.

\section{Results}

The data in Table 1 shows that the highest min gray scale value among the samples in the study was exhibited by amalgam $(10,160.20 \pm 1,766.53$; 95\% CI: 8,896.50-11,423.90). Dycal exhibited the lowest min gray scale value among the restorative materials in the study $(4,861.00 \pm 1,159.35$; $95 \%$ CI: 4,031.65-5,690.35). Based on a one-way ANOVA, the 5 restorative materials in the study showed significant differences in the min gray scale values $(\mathrm{p}=0.001)$.

The data in Table 1 shows that the highest max gray scale value was exhibited by amalgam (14,554.1 \pm 2927.9 ; 95\% CI: 12,459.63-16,648.57). The lowest max gray scale value belonged to glass-ionomer $(8,192.29 \pm 4,172.52$; $95 \%$ CI: 4,333.34-12,051.23), indicating a significant difference in the max gray scale values based on a one-way ANOVA $(\mathrm{p}=0.001)$.

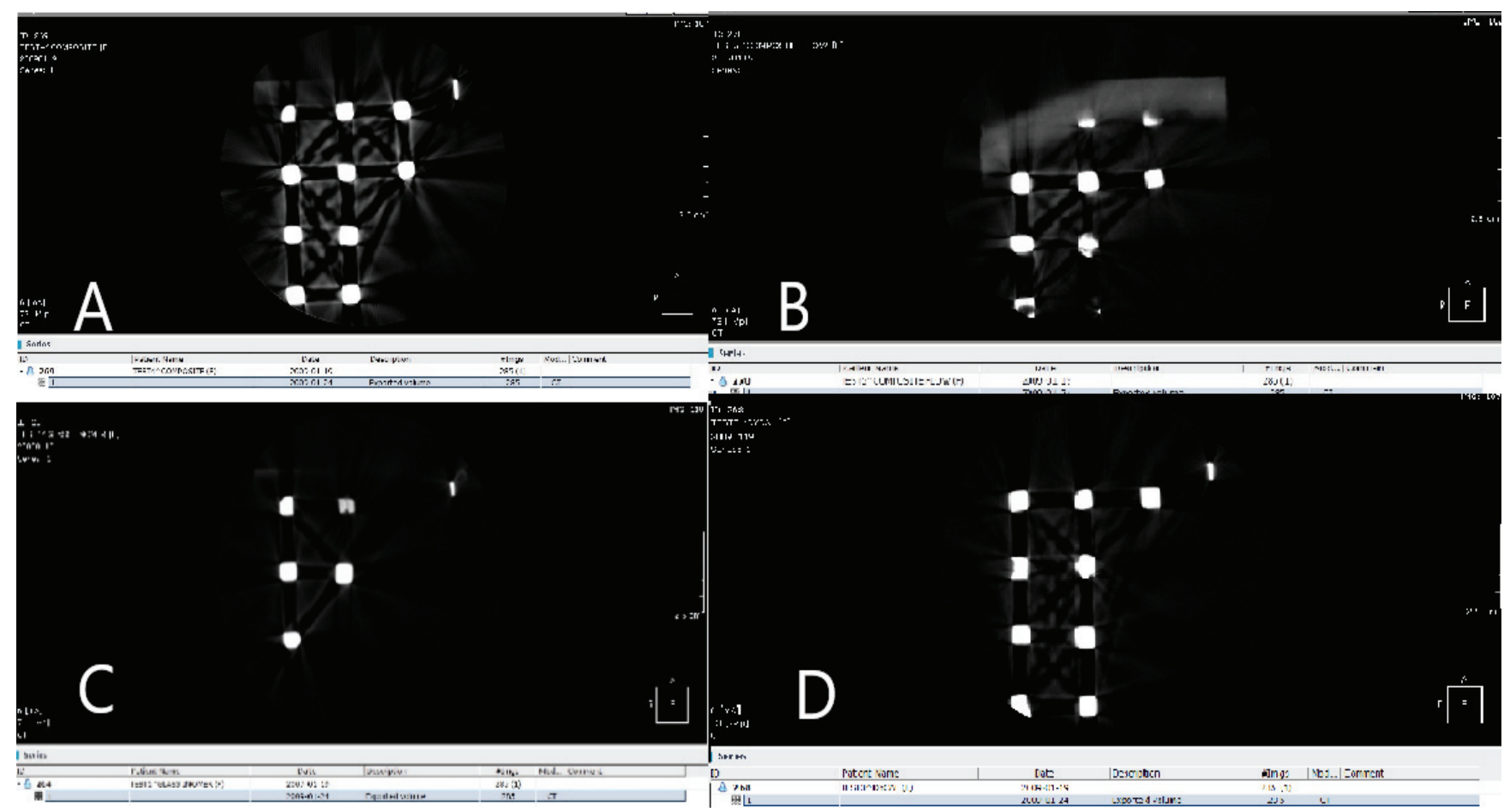

Fig. 6. The cone-beam computed tomography (CBCT) images of: A - composite resin; B - flowable composite resin; C - glass-ionomer; D - Dycal cubes, scanned by a Kodak CBCT system 
Table 1. Comparison of the min and max gray scale values in 5 restorative materials

\begin{tabular}{|c|c|c|c|c|c|c|c|c|c|}
\hline \multicolumn{10}{|c|}{ Descriptives } \\
\hline \multirow{2}{*}{\multicolumn{2}{|c|}{ Types of dental materials }} & \multirow{2}{*}{$\mathrm{n}$} & \multirow{2}{*}{ mean } & \multirow{2}{*}{ SD } & \multicolumn{2}{|c|}{$95 \% \mathrm{Cl}$} & \multirow{2}{*}{$\min$} & \multirow{2}{*}{$\max$} & \multirow{2}{*}{$p$-value } \\
\hline & & & & & lower bound & upper bound & & & \\
\hline \multirow{5}{*}{ Min } & amalgam & 10 & $10,160.20$ & $1,766.53$ & $8,896.50$ & $11,423.90$ & $7,703.00$ & $13,193.00$ & \multirow[t]{5}{*}{0.001} \\
\hline & composite & 10 & $7,248.90$ & $2,690.49$ & $5,324.24$ & $9,173.56$ & $2,839.00$ & $11,188.00$ & \\
\hline & composite flow & 10 & $6,491.40$ & $3,279.22$ & $4,145.59$ & $8,837.21$ & $1,723.00$ & $10,544.00$ & \\
\hline & glass-ionomer & 7 & $6,248.14$ & $3,582.88$ & $2,934.53$ & $9,561.75$ & 232.00 & $9,639.00$ & \\
\hline & Dycal & 10 & $4,861.00$ & $1,159.35$ & $4,031.65$ & $5,690.35$ & $2,864.00$ & $6,494.00$ & \\
\hline \multirow{5}{*}{ Max } & amalgam & 10 & $14,554.10$ & $2,927.87$ & $12,459.63$ & $16,648.57$ & $10,474.00$ & $19,335.00$ & \multirow{5}{*}{0.001} \\
\hline & composite & 10 & $9,306.00$ & $3,017.59$ & $7,147.35$ & $11,464.65$ & $4,263.00$ & $14,888.00$ & \\
\hline & composite flow & 10 & $9,457.30$ & $4,713.73$ & $6,085.30$ & $12,829.30$ & $4,476.00$ & $18,368.00$ & \\
\hline & glass-ionomer & 7 & $8,192.29$ & $4,172.52$ & $4,333.34$ & $12,051.23$ & $1,906.00$ & $14,798.00$ & \\
\hline & Dycal & 10 & $8,269.60$ & $2,081.21$ & $6,780.80$ & $9,758.40$ & $5,816.00$ & $12,905.00$ & \\
\hline \multirow{5}{*}{ Mean } & amalgam & 10 & $11,253.70$ & $1,706.37$ & $10,033.03$ & $12,474.37$ & $8,433.00$ & $13,765.00$ & \multirow[t]{5}{*}{0.009} \\
\hline & composite & 10 & $8,217.50$ & $2,768.59$ & $6,236.97$ & $10,198.03$ & $3,644.00$ & $12,503.00$ & \\
\hline & composite flow & 10 & $7,713.10$ & $3,698.44$ & $5,067.39$ & $10,358.81$ & $2,660.00$ & $12,286.00$ & \\
\hline & glass-ionomer & 7 & $7,252.57$ & $3,835.23$ & $3,705.57$ & $10,799.57$ & $1,276.00$ & $12,583.00$ & \\
\hline & Dycal & 10 & $6,692.80$ & $1,837.25$ & $5,378.51$ & $8,007.09$ & $4,145.00$ & $10,927.00$ & \\
\hline
\end{tabular}

SD - standard deviation; Cl - confidence interval.

The analysis of the mean gray scale values of the restorative materials (Table 1) shows that the highest value was displayed by amalgam $(11,253.7 \pm 1706.37$; $95 \%$ CI: 10,033.03-12,474.37). The lowest mean gray scale value was found in Dycal $(6,692.80 \pm 1,837.25$; 95\% CI: 5,378.51-8,007.09), indicating a statistically significant difference in the mean gray scale values among the 5 restorative materials in this study based on a one-way ANOVA ( $\mathrm{p}=0.009)$.

Post-hoc Tukey's tests were used to compare the min, max and mean gray scale values. Using pair-wise analyses of the restorative materials, it was concluded that the min value of amalgam was significantly different from all the other materials except for composite resin. It is worth noting that flowable composite resin exhibited a borderline significant difference from amalgam in the min gray scale value.

Regarding the gray scale max value, in pair-wise comparisons of the restorative materials, amalgam exhibited the following statistically significant differences from the other materials: composite resin $(\mathrm{p}=0.013)$, flowable composite resin $(p=0.016)$, glass-ionomer $(p=0.005)$, and Dycal ( $\mathrm{p}=0.002)$. Amalgam had the highest max gray scale value of all the materials. Other materials, however, did not show a statistically significant difference in the above test $(\mathrm{p}>0.05)$.

Table 2. The min, max and mean gray scale values in different brands of 5 restorative materials

\begin{tabular}{|c|c|c|c|c|c|c|c|c|c|c|c|c|c|c|c|}
\hline \multirow{3}{*}{ Brands* } & \multicolumn{15}{|c|}{ Type of dental material } \\
\hline & \multicolumn{3}{|c|}{ amalgam } & \multicolumn{3}{|c|}{ composite } & \multicolumn{3}{|c|}{ flowable composite } & \multicolumn{3}{|c|}{ glass-ionomer } & \multicolumn{3}{|c|}{ Dycal } \\
\hline & $\min$ & $\max$ & mean & $\min$ & $\max$ & mean & $\min$ & $\max$ & mean & $\min$ & $\max$ & mean & $\min$ & $\max$ & mean \\
\hline A & 11,435 & 16,427 & 12,521 & 2,839 & 4,263 & 3,644 & 3,809 & 5,418 & 4,907 & 4,031 & 5,440 & 4,785 & 6,494 & 8,883 & 7,368 \\
\hline B & 11,264 & 19,335 & 12,703 & 7,491 & 9,497 & 8,498 & 9,052 & 10,567 & 9,552 & 5,690 & 6,924 & 6,243 & 5,401 & 7,148 & 6,144 \\
\hline C & 11,838 & 19,011 & 13,207 & 6,342 & 7,897 & 7,091 & 6,891 & 7,961 & 7,359 & 9,602 & 14,798 & 12,583 & 4,888 & 6,832 & 5,931 \\
\hline D & 9,220 & 12,069 & 10,150 & 10,313 & 11,613 & 10,972 & 10,434 & 13,687 & 11,563 & 232 & 1,906 & 1,276 & 4,804 & 12,905 & 10,927 \\
\hline$E$ & 9,591 & 12,326 & 10,425 & 6,731 & 9,479 & 7,975 & 7,851 & 18,368 & 12,286 & 9,639 & 10,670 & 10,034 & 5,297 & 9,802 & 5,940 \\
\hline $\mathrm{F}$ & 9,849 & 13,837 & 10,801 & 4,397 & 6,298 & 5,237 & 8,318 & 12,103 & 10,061 & 9,591 & 10,422 & 9,970 & 5,008 & 7,689 & 6,381 \\
\hline G & 7,771 & 13,955 & 9,842 & 6,416 & 8,484 & 7,386 & 2,601 & 4,510 & 3,325 & 4,952 & 7,186 & 5,877 & 2,864 & 5,816 & 4,145 \\
\hline $\mathrm{H}$ & 9,738 & 13,115 & 10,690 & 10,415 & 12,082 & 11,456 & 10,544 & 12,318 & 11,293 & - & - & - & 6,050 & 7,618 & 6,663 \\
\hline I & 13,193 & 14,992 & 13,765 & 6,357 & 8,559 & 7,413 & 3,691 & 4,476 & 4,125 & - & - & - & 4,819 & 6,498 & 5,308 \\
\hline$J$ & 7,703 & 10,474 & 8,433 & 11,188 & 14,888 & 12,503 & 1,723 & 5,165 & 2,660 & - & - & - & 2,985 & 9,505 & 8,121 \\
\hline
\end{tabular}

* The letters A-J represent different brands according to the description in section "Material and methods". 
The results of pair-wise analyses of the mean gray scale values showed that amalgam was significantly different from glass-ionomer $(\mathrm{p}=0.048)$ and Dycal $(\mathrm{p}=0.007)$. The difference between amalgam and flowable composite resin was borderline significant $(\mathrm{p}=0.057)$, while the difference between amalgam and composite resin was not significant ( $p=0.136)$. Based on Tukey's honest significant difference (HSD) tests, the other restorative materials did not exhibit significant differences in the mean values in pair-wise comparisons.

Amalgam had higher min, max and mean gray scale values than the other restorative materials. It exhibited the same gray scale value as composite resin in some cases, but was significantly different from glass-ionomer, Dycal and flowable composite resin. It can be concluded that composite resin and amalgam were high in gray scale, and flowable composite, glass-ionomer and Dycal exhibited low gray scale.

Table 2 presents the min, max and mean gray scale values of the restorative materials in terms of their brands. The results show that among the amalgam samples, Kerr had the highest min and mean values, and SDI had the highest max gray scale value compared to the other brands.

Among the composite brands, Dentkist exhibited the highest min, max and mean gray scale values, and the lowest values belonged to SDI.

Among the flowable composite resins, the highest max and mean gray scale values belonged to Kuraray, and the highest min gray scale level was found in Ivoclar Vivadent, India. The lowest min nad mean gray scale values belonged to $3 \mathrm{M}$, and the lowest max gray level belonged to SDI.

Out of the 7 glass-ionomer brands, the highest max and mean gray scale values belonged to Tokuyama, and the lowest values were found in Dentsply.

In Dycal, the highest min gray scale value belonged to Pulpdent Corporation, and the lowest max, min and mean values belonged to DMG Chemisch-Pharmazeutische.

The min, max and mean gray scale values of different restorative materials in terms of their brands are presented in Fig 7-9.

The min gray scale value was higher in amalgams than in the other restorative materials. Glass-ionomer and Dycal had a lower value than the other restorative materials. Composite resin and flowable composite resin were in the middle of the range.

Among the amalgam samples, the max gray value belonged to SDI and the min value belonged to Anas Dental Supplies. Among the composite resins, the max was found in Dentkist and the min was noted in SDI. Flowable composite resins showed their max and min values in Kuraray and 3M, respectively. Glass-ionomer exhibited the max and min values in Tokuyama and Dentsply, respectively. Finally, in Dycal, the max and min gray scale values belonged to Meta Biomed and DMG ChemischPharmazeutische, respectively.

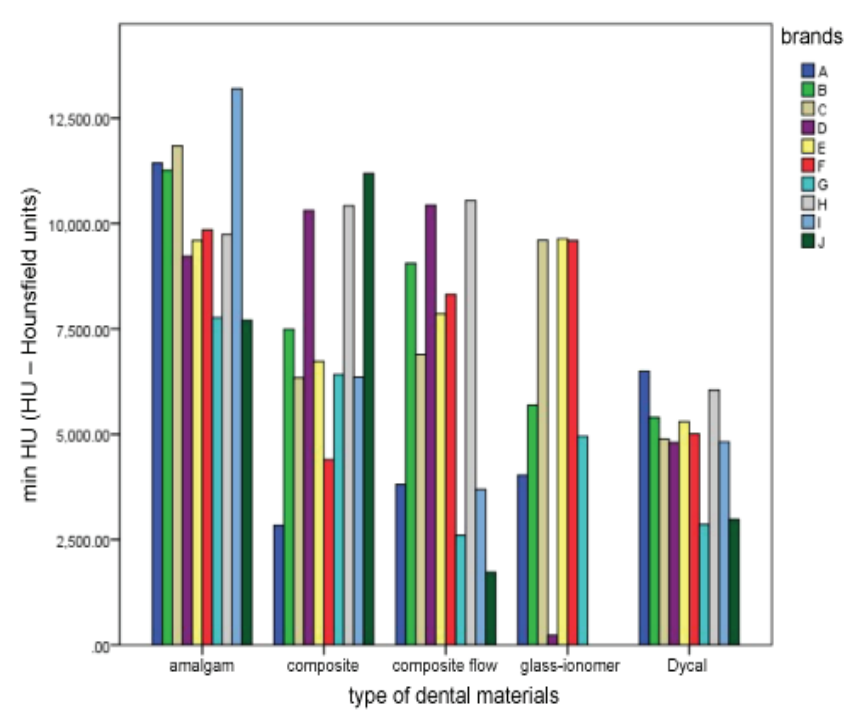

Fig. 7. Minimum gray scale values of restorative materials in relation to their brands

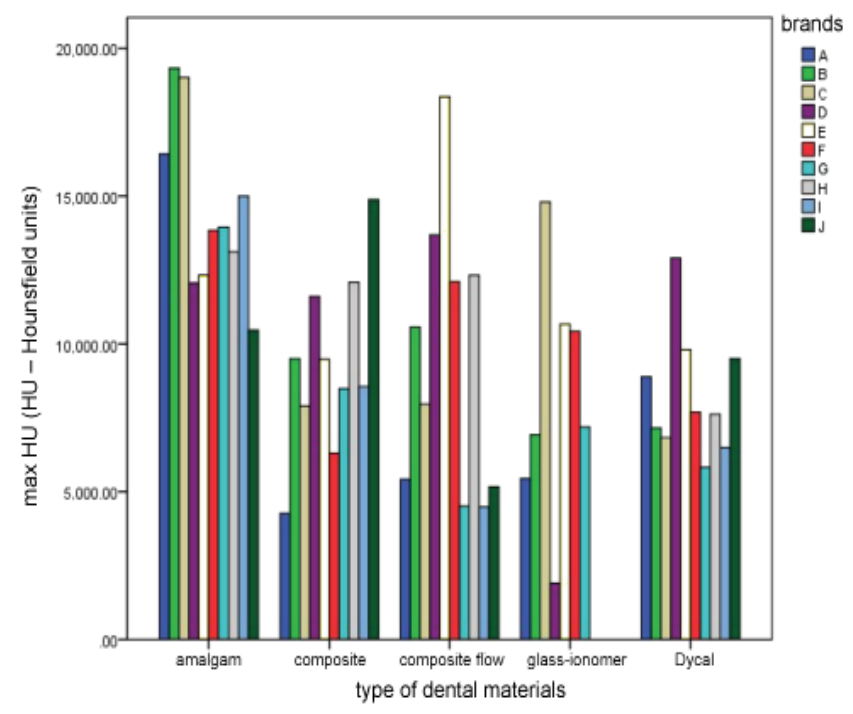

Fig. 8. Maximum gray scale values of restorative materials in relation to their brands

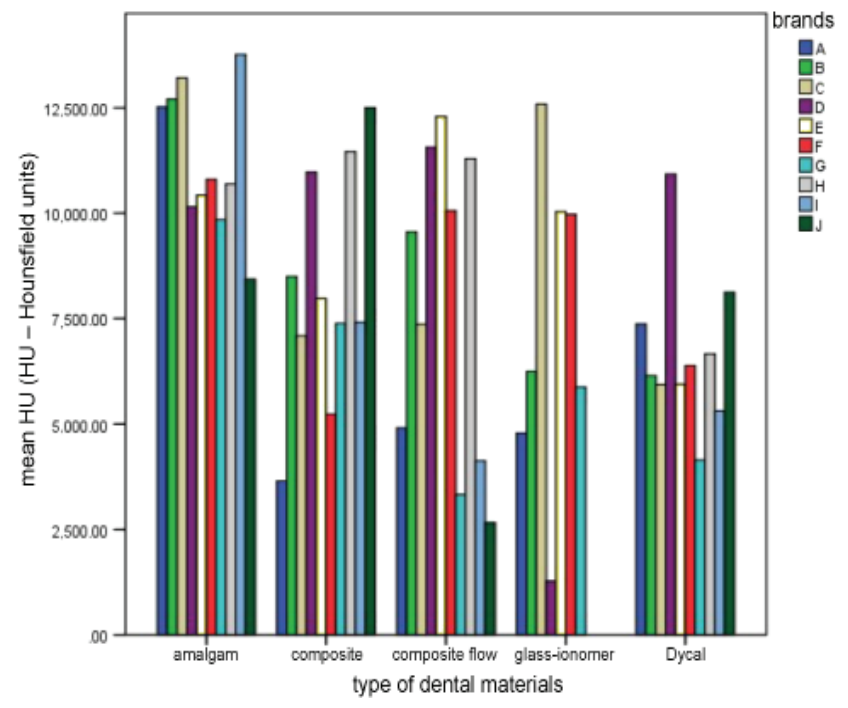

Fig. 9. Mean gray scale values of restorative materials in relation to their brands 


\section{Discussion}

Cone-beam computed tomography has been used as an important diagnostic tool in recent years..$^{9-13}$ It is an innovative method in scanning and image reconstruction. In this technique, materials with different densities, such as bone and soft tissue, can be differentiated based on their densitometry. Several studies have been conducted in this regard, but only a few have evaluated the density of restorative materials commonly used in dentistry.

Among these studies, Lachowski et al. analyzed the radiopacity of various dental materials (bases and liners). ${ }^{16}$ They used digital intraoral radiography (Kodak; radiovisiography (RVG): 5000, 70 kVp, 7 mA, 0.32 s, 30-centimeter distance). As in the present study, Tetric N-flow was among the flowable composite resins. With a thickness of $3 \mathrm{~mm}$, this material exhibited the highest gray scale. It had the second highest gray scale value in the present study, consistent with the results of the study by Lachowski et al. It must be pointed out that the gray scale value of a material is directly related to its density. Considering this and the results of the present study, in the category of flowable composite resins, the lowest gray scale value belonged to the most flowable one. The same cannot be said with certainty regarding glass-ionomers, because they are supplied as 2-part powder and liquid systems that require mixing, depending on their different therapeutic applications. Glass-ionomers are sometimes used in a creamy consistency to line dental caries, but in class $\mathrm{V}$ restorations on the root surface, they are used in a thicker consistency.

By scanning samples of different sizes, Lachowski et al. concluded that the thickness of the samples had a direct effect on the final radiography. Thicker samples had a greater amount of substance, and thus more X-ray attenuation was observed ${ }^{16}$. In the present study, all the samples for scanning were prepared in the same dimensions and their thickness was fixed at $5 \mathrm{~mm}$. In addition, the sub-categories of each group of restorative materials were compared to each other in terms of the min and max gray scale values, with a direct relation between density and gray scale values resulting from the CBCT images.

Although intraoral digital imaging is less costly than CBCT, since it does not provide a value level as the output of the radiopacity analysis, the materials in the study by Lachowski et al. were measured with a single opaque item. In that study, the opacity of the materials in aluminum sheets of different thicknesses were evaluated. The ingredients of aluminum sheets vary and this affects their opacity. Furthermore, the opacity of the study samples, compared to the opaque aluminum sheet, was evaluated with the use of relative measurements. ${ }^{16}$ However, in the present study, the $\mathrm{CBCT}$ technique was used to capture images, which had the advantage of higher resolution and accuracy compared to other imaging systems.
In another study, Devito et al. compared the radiopacity of 3 types of calcium hydroxide (Dycal, Hydro-C, Life) using digital radiography. They concluded that the radiopacity of the cement and enamel was equal to $2 \mathrm{~mm}$ of aluminum, but the radiopacity of the dentin was equal to $1 \mathrm{~mm}$ of aluminum. In that study, the lowest opacity belonged to Life. ${ }^{17}$ In the present study, among the 10 different types of Dycal, the least opacity was noted for Ionosit-Baseliner and the highest for Biner-LC. Hidrox-Cal, which was assessed both in this study and in the study by Devito et al., was in the middle of the spectrum.

Pires de Souza et al. investigated the optical densities of calcium hydroxide and glass-ionomer, concluding that in order to assess the radiopacity of different materials, the min thickness of the samples must be approx. $1.5-2 \mathrm{~mm} .{ }^{18}$ In the present study, the thickness of each sample was $5 \mathrm{~mm}$. It is consistent with the above-mentioned authors, who used intraoral radiography to examine the opacity of the materials.

In research conducted by Imperiano et al., intraoral radiography and materials of equal thickness $(2 \times 10 \mathrm{~mm})$ were used to measure the density of different composite resin types. In that study, Natural Flow and Protect Liner F composite resins did not exhibit any specific opacity that would allow them to be differentiated from dental caries. ${ }^{19}$ However, in the present study, none of the composite resins exhibited a significant difference from amalgam and all had the necessary opacity for differentiation from the tooth structure. This discrepancy between the results of studies might be attributed to differences in research methods. In addition, none of the brands evaluated in the present study was used in the study by Imperiano et al.

Factors affecting the results obtained from CBCT include the scanning conditions and the type of device. .,8,20,21 $^{-}$ Therefore, to determine the gray scale of different restorative dental materials, a single CBCT device was used.

As discussed above, in the CT technique one number is assigned to each pixel, which indicates the amount of radiation attenuated by the studied tissue. ${ }^{8}$ This is one of the differences between $\mathrm{CT}$ and $\mathrm{CBCT}$, and the lack of real $\mathrm{HU}$ (as in CT) is a disadvantage of CBCT. Mah et al. examined the different structures of 11 dental CBCT units and 2 medical CT systems. The results showed that there was a high correlation between $\mathrm{HU}$ in $\mathrm{CT}$ and the gray scale in $\mathrm{CBCT}{ }^{21}$ In the present study, $\mathrm{CBCT}$ was used instead of $\mathrm{CT}$ due to its greater advantages, such as low-dose radiation, high precision in supplying images at shorter scan times, higher resolution and clarity, and lower cost compared to medical CT.

In a study by Razi et al., the soft tissue of a sheep's head was used. ${ }^{4}$ Mah et al. placed specimens in a bowl of water in order to simulate soft tissue to some extent for X-ray attenuation. ${ }^{21}$ However, Parsa et al. used a dry mandible. ${ }^{20}$ In the present study, an attempt was made to obtain a number for the gray scale value of the restorative materials by eliminating confounding factors, such as facial soft tissue, tongue and saliva in order to provide a background for future studies. 
In another study, Emadi et al. compared different samples of restorative materials and reported that amalgam and AH-26 had the highest gray scale value. Zinc phosphate, gutta-percha and zinc oxide eugenol had the second place, followed by MTA and polycarboxylate. ${ }^{8}$ In the present study, amalgam, composite resin, flowable composite resin, glass-ionomer, and Dycal were studied, and the highest gray scale value was noted for amalgam; this was consistent with the results reported by Emadi et al. In the present study, Dycal exhibited the lowest gray scale.

\section{Conclusions}

The results of the present study show that CBCT can be efficient in differentiating amalgam and composite resin from other materials, such as flowable composite resin, glass-ionomer and Dycal. This is a pilot study; therefore, in further studies we will compare this value in different CBCT and multi-row-detector computed tomography (MDCT) systems.

\section{References}

1. Arisan V, Karabuda ZC, Avsever H, Özdemir T. Conventional multi-slice computed tomography (CT) and cone beam CT (CBCT) for computer assisted implant placement. Part I: Relationship radiographic gray density and implant stability. Clin Impl Dent Rel Res. 2013;15(6):893-906.

2. Aras MH, Miloglu O, Barutcugil C, Kantarici M, Ozcan E, Harorli A. Comparison of the sensitivity for detecting foreign bodies among conventional plain radiography, computed tomography and ultrasonography. Dentomaxillofac Radiol. 2010;39(2):72-78.

3. White SC, Pharoah MJ. Oral Radiology: Principles and Interpretation. $5^{\text {th }}$ ed. St. Louis, MO: Mosby; 2009:207-211.

4. Razi T, Niknami M, Alavi Ghazani F. Relationship between Hounsfield unit in CT scan and gray scale in CBCT. J Dent Res Dent Clin Dent Prospects. 2014;8(2):107-110.

5. Katsumata A, Hirukawa A, Okumura S, et al. Relationship between density variability and imaging volume size in cone-beam computerized tomographic scanning of the maxillofacial region: An in vitro study. Oral Surg Oral Med Oral Pathol Oral Radiol Endod. 2009;107(3):420-425.

6. Lagravère MO, Carey J, Ben-Zvi M, Packota GV, Major PW. Effect of object location on the density measurement and Hounsfield conversion in a NewTom $3 \mathrm{G}$ cone beam computed tomography unit. Dentomaxillofac Radiol. 2008;37(6):305-308.

7. Oliveria ML, Freitas $D Q$, Ambrosano GM, Haiter-Neto F. Influence of exposure factors on the variability of $C B C T$ voxel values: A phantom study. Dentomaxillofac Radiol. 2014;43(6):20140128.

8. Emadi N, Safi Y, Akbarzadeh Bagheban A, Asgary S. Comparison of CT-number and gray scale value of different dental materials and hard tissues in CT and CBCT. Iran Endod J. 2014;9(4):283-286.

9. Esmaeili F, Johari M, Haddadi P, Vatankhah M. Beam hardening artifacts: Comparison between two cone-beam computed tomography scanners. Dent Res Dent Clin Dent Prospects. 2012;6(2):2-7.

10. Chindasombatjareon J, Kakimoto N, Murakami S, Maeda Y, Furukawa S. Quantitative analysis of metallic artifacts caused by dental metals: Comparison of cone-beam and multi-detector row CT scanners. Oral Radiol. 2011;27:114-120.

11. Ludlow JB, Ivanovic M. Comparative dosimetry of dental CBCT devices and 64-slice CT for oral and maxillofacial radiology. Oral Surg Oral Med Oral Pathol Oral Radiol Endod. 2008;106(1):930-938.

12. Ludlow JB, Davis-Ludlow LE, Brooks SL, Howerton WB. Dosimetry of 3 CBCT devices for oral and maxillofacial radiology: $C B$ Mercuray, NewTom 3G and i-Cat. Dentomaxillofac Radiol.2006;35(4):219-226.
13. Schulze RK, Berndt D, d'Hoedt B. On cone-beam computed tomography artifacts induced by titanium implants. Clin Oral Implant Res. 2010;21(1):100-107.

14. Zöller JE, Neugebauer J. Cone-beam Volumetric Imaging in Dental, Oral and Maxillofacial Medicine: Fundamentals, Diagnostics and Treatment Planning. London, UK: Quintessence Publishing; 2008:27-35.

15. Haristoy RA, Valiyaparambil JV, Mallya SM. Correlation of CBCT gray scale values with bone densities. Oral Surg Oral Med Oral Pathol Oral Radiol Endod. 2009;107(4):28-35.

16. Lachowski KM, Botta SB, Lascala CA, Matos AB, Sobral MA. Study of the radio-opacity of base and liner dental materials using a digital radiography system. Dentomaxillofac Radiol. 2013;42(2):20120153.

17. Devito KL, Ortega Al, Haiter Neto F. Radiopacity of calcium hydroxide cement compared with human tooth structure. J Appl Oral Sci. 2004;12(4):290-293.

18. Pires de Souza FC, Pardini LC, Cruvinel DR, Hamida HM, Garcia LFR. In vitro comparison of the radiopacity of cavity lining materials with human dental structures. J Conserv Dent. 2010;13(2):65-70.

19. Imperiano $M T$, Jamil Khoury $H$, Anjos Pontual ML, Japiassú Resende Montes MA, Fonseca Silveira MM. Comparative radiopacity of four low viscosity composites. Braz J Oral Sci. 2007;6(20):20-26.

20. Parsa A, Ibrahim N, Hassan B, Motroni A, van der Stelt P, Wismeijer D. Influence of cone beam CT scanning parameters on grey value measurements at an implant site. Dentomaxillofac Radiol. 2013;42(3):79884780.

21. Mah P, Reeves TE, McDavid WD. Deriving Hounsfield units using grey levels in cone beam computed tomography. Dentomaxillofac Radiol. 2010;39(6):323-335. 